\title{
WhatsApp Emoji in Business Interactions: The Case of Malaysian and Iranian Interactions
}

\author{
Rohayah Kahar \& Hadina Habil \\ Language Academy, Universiti Teknologi Malaysia, 81310 UTM Johor Bahru, Johor, Malaysia \\ Submitted: 7/11/2020. Revised edition: 15/12/2021. Accepted: 15/12/2021. Published online: 15/12/2021
}

\begin{abstract}
WhatsApp emoji has been widely used by users all over the world especially entrepreneurs during their business interactions. In these interactions, WhatsApp emoji has been discovered to be intriguing. Emoji, among other things, was used to replace nonverbal expressions in face-to-face interactions especially during business communications. However, studies related to the usage of WhatsApp emoji in business interactions were found to be limited, particularly in the Malaysian setting. Thus, the purpose of this research was to examine the use of WhatsApp emoji in business communications between a Malaysian entrepreneur and three Iranian counterparts. Content Analysis was used to interpret the messages in the business conversations, and the data were analysed using De Vito's Five-Stage Model of Conversation. The findings revealed that WhatsApp emoji performed a range of functions in business interactions in a BELF setting. In short, WhatsApp has clearly added some useful and valuable features for a variety of uses, including business communications.
\end{abstract}

Keywords: Emoji, WhatsApp, business, interactions, BELF

\subsection{INTRODUCTION}

English is frequently used as a medium of intercultural communication due to the fast-expanding number of English speakers from various cultural backgrounds all over the world (Sharifian, 2014; Babai Shishavan \& Sharifian, 2016). Global communications, in line with modern development, are essential for people especially entrepreneurs to extend their business internationally. As a result, they will need to engage with people all around the world through virtual communication technologies like WhatsApp. Along with the use of social media among entrepreneurs, English is needed as it is an international language. Therefore, English plays a vital role for Small and Medium Enterprises (SMEs) in Malaysia to communicate with international entrepreneurs. Additionally, emoji has gained popularity in recent years, and it is now one of the most widely used multimedia tools. Emoji usage in business communication can assist both entrepreneurs and customers in a range of ways. Emoji characters, which are considered authentic expressions, helps entrepreneurs in developing relationships with customers. Additionally, using emoji in a business context shows to customers that the entrepreneurs

\footnotetext{
*Correspondence to: Rohayah Kahar (email: rohayahkahar@utm.my)
} 
are trustworthy and approachable (Business.com, 2020). At present, there is emerging research on emoji in business life (Mert, 2020). For instance, emoji is used in brand communication (CasadoMolina, Garcia, Alarcón-Urbistondo, \& Romero-Charneco, 2019), online review in tourism (Huang, Chang, Bilgihan, \& Okhomus, 2020), emoji and brand engagement (McShane, Pancer, Poole, \& Deng, 2020). Apart from that, Robinson (2019) suggests emoji acts as an innovative business communication. Nonetheless, in the Malaysian environment, emoji research has been focusing more on cultural issues (Intan \& Yasir, 2020). Little research has been conducted on the use of emoji in business interactions.

Therefore, this study aimed to find out the usage of WhatsApp emoji in business interactions between a Malaysian entrepreneur and the three Iranian business counterparts. Specifically, the objectives of the paper are as follows: (1) To investigate the usage of WhatsApp emoji in business interactions and (2) To classify the functions of WhatsApp emoji using De Vito's Five-Stage Model of Conversation.

\subsection{LITERATURE REVIEW}

Emoji's popularity has grown in recent years, and it is currently one of the most extensively used multimedia tools. According to Skiba (2016), Shigetaka Kurita created emoji in Japan in the late 1990s to provide contextual stimuli and interpersonal value on a mobile internet network. Rather than the English word expression, the term emoji is derived from the Japanese character e (絵, "picture") + moji (文字, “character’) (Skiba, 2016).

In terms of the taxonomy of emoji's pragmatic functions or emoticons, Yus (2014) presented an 8-function emoji taxonomy, which is the broadest and most comprehensive coverage so far. The taxonomy of emoji functions is shown in the table below:

Table 1 The 8-Functions Taxonomy of Emoji (Yus, 2014)

\begin{tabular}{|ll|}
\hline & \multicolumn{1}{|c|}{ No. The Functions } \\
\hline 1. & $\begin{array}{l}\text { To signal the propositional attitude underlying the utterance and difficult to identify without the assistance of the } \\
\text { emoticon. }\end{array}$ \\
\hline 2. & To express a higher intensity of a propositional attitude that is already coded verbally. \\
\hline 3. & To strengthen/reduce the illocutionary force of a speech act. \\
\hline 4. & To counter the explicit content of the utterance (humor). \\
\hline 5. & To contradict the explicit content of the utterance (irony). \\
\hline 6. & To add a feeling or emotion towards the utterance's propositional content (affective attitude toward the utterance). \\
\hline 7. & To add an emotion or feeling to the overall communicative act (feeling or emotion in parallel to the communicative act). \\
\hline 8 & To communicate the strength of a feeling or emotion that was coded verbally \\
\hline
\end{tabular}


Emoji acts as a window on how online social life participants demonstrate proficiency in Internetbased conversation management ( $\mathrm{Li} \&$ Yang, 2018). Therefore, it is based on how individuals perceive and comprehend the meaning of the emoji used. Thus, emoji can be used for a variety of purposes in WhatsApp and other social networking platforms.

In the business world, emoji continues to play a key role in business communication procedures such as messaging and chat. Emoji is an effective tool for even more clearly expressing people's sentiments and reactions than written communication (Zeybek, 2017; Mert, 2020). Emojis are considered authentic expressions, and they help entrepreneurs develop relationships with customers. Furthermore, by using emoji in a business context, it gives customers the impression that entrepreneurs are reliable and reachable (business.com, 2020). Adobe (2019) conducted the most comprehensive research on emoji usage in the business world, and the results of its emoji research were published in the Emoji Trend Report in 2019. According to the survey, 62 percent of users say the major reason they use emoji in the business interaction is to make the environment and their talks more enjoyable. Emojis, according to 42 percent of users, express their feelings and thoughts better than words. Thirty-one percent of customers believe that utilising emoji in their conversation speeds up communication.

Due to the massive increasing number of English speakers from many cultural backgrounds all over the world, English is widely utilised as a means of intercultural communication (Sharifian, 2014; Babai Shishavan \& Sharifian, 2016). Intercultural communication describes interactions between individuals who speak different languages yet communicate in the same language. Interpersonal communication consists of seven components: communicators, messages, noise, feedback, context, ethics, and channel (DeVito, 2013). These components work together to deliver communications from one person to another (Hendrith, 2018). Iran, for instance, has employed Business English in business dealings. Hence, global communications, in keeping with modern development, are critical for entrepreneurs looking to expand their business globally. Consequently, they will need to use online communication tools like WhatsApp to engage with people all over the world.

Social media research and digital technology are being conducted to find out its impact on communication. One such research is qualitative research on digital technology to show its influence in tourism business (Sharma, Sharma, \& Chaudhary, 2020). Apart from that, social media interactions in business setting were also conducted such as, brand association (Parganas, Anagnostopoulos, \& Chadwick, 2017) and business-to-business marketing (Huotari, Ulkuniemi, Saraniemi, \& Tormala, 2015) while in the study of language, language choice was also a main concern during social media interactions (Jakic, Wagner, \& Meyer, 2017). The previous research displays the importance of social media in business communication.

De Vito's Five-Stage Model of Conversation was used as a foundation of the study. These stages included the following: Opening, Feedforward, Business, Feedback, and Closing. Conversation, according to De Vito (2011), is a process rather than an act. It is helpful to separate this process into chunks or phases, with each stage needing a decision about what to say and how to say it. The fivestage model of communication is depicted in the figure below: 


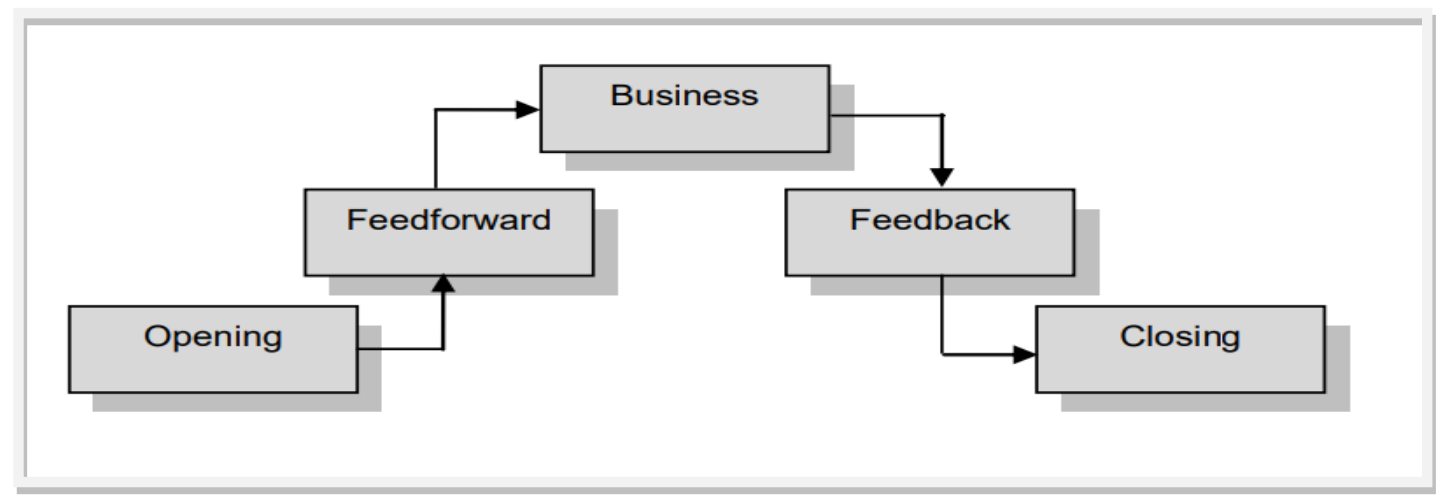

Figure 1 A Five-Stage Model of Converation (DeVito, 2011)

These stages and the way people follow them will differ depending on the communicators' personalities, the context in which the conversation takes place, the purpose of the conversation, and a variety of other factors considered throughout this text (DeVito, 2011; Herwinda, 2012):

1. Opening

The first step is to initiate the conversation, which is usually done with greetings such as "Hello!" and "Hi, how can I help you?" This step establishes a link between two people and paves the way to more meaningful interaction (DeVito, 2011; Herwinda, 2012).

\section{Feedforward}

It provides some kind of feedforward during the second step, giving the other person a general idea of the conversation's focus (DeVito, 2011; Herwinda, 2012). In other words, the person needs to communicate prior to communicating. In this context, it is where customers or entrepreneurs state their primary reason for initiating the conversation, such as purchasing a product in a business interaction.

3. Business

The third step is to get down to "business," which is the substance or focus of the conversation. The term business is used to emphasise that most conversations have a specific goal in mind. In general, the agreement is carried out through the exchange of speaker and listener roles (DeVito, 2011; Herwinda, 2012).

4. Feedback

The fourth step is feedback, which is the inverse of the second. In this case, it is common practice to reflect on the conversation to indicate that the business is finished (DeVito, 2011; Herwinda, 2012). For example, "Give me your account number for me to pay". 


\section{Closing}

The final step is the opposite of the first, which is the closing. This frequently reveals how pleased the person was with the conversation, such as "Thank you" (DeVito, 2011; Herwinda, 2012). It is also used to schedule future conversations, such as "I will notify you once I have shipped the products."

Consequently, the focus of this study was on interactions between a Malaysian SME and three Iranian business counterparts in a Business English as a Lingua Franca (BELF) setting.

\subsection{METHOD}

A qualitative approach was used for the study. Based on the findings, the researchers selected four participants for the qualitative method involving a Malaysian SME and Iranian businessmen. These participants were thoroughly researched in terms of their social media usage as well as their conversations with international business counterparts. Furthermore, the interactions of social media usage in a BELF setting were the basis of the study. Several factors had been used to select the participants, including their usage of English in business, the fact that their first tongue was not English, and whether they had commercial dealings with international counterparts. They were discovered on one of the SME's social media platforms (Facebook, Instagram, or WhatsApp). They were asked to give consent via WhatsApp after indicating their willingness to participate in the study. The type of social media that was employed in the study is WhatsApp. Interactions between the SME and business counterparts engaging in social media conversations were studied and analysed for three months, or until the transaction was completed.

In a BELF setting, this research examined interactions between a Malaysian SME and his three Iranian business counterparts. A Malaysian SME specialising in souvenirs, interior decorations, and tourism was one of the participants involved. He was seeking to expand his business by going online. The business counterparts included three Iranians in which one of them is a national residing in Malaysia and the other two are Iranians who are currently doing online business through social media. To analyse the data, the researchers employed Qualitative Content Analysis procedure (Zhang \& Wildemuth, 2005; Bengtsson, 2016; Erlingsson \& Brysiewicz, 2017). In this procedure, the data from WhatsApp conversations of the SMEs were transcribed. Following this, two raters (coders) were selected. Then, they looked for keywords and came up with the codes. Later, they came together to confirm and merge the codes. After this, codebooks with the themes and codes were developed. Finally, interpretations were made based on the themes and codes developed. Qualitative Content Analysis Software by Mayring (2014) helped to facilitate the process. The data were analysed based on De Vito's Five-Stage Model of Conversation involving Opening, Feedforward, Feedback, and Closing stages. 


\subsection{RESULTS AND DISCUSSION}

The findings are described according to each stage. The study discovered the use of WhatsApp emoji in business interactions between a Malaysian SME and his three Iranian counterparts.

\begin{tabular}{|c|c|c|c|c|c|c|c|c|c|c|c|c|c|}
\hline NO. & $\begin{array}{ll}\text { TYPES } & \text { OF } \\
\text { EMOJI } & \end{array}$ & M2 & $\begin{array}{l}\mathrm{F} \\
\mathrm{Q}\end{array}$ & IA & FQ & M2 & FQ & IB & FQ & M2 & $\begin{array}{l}\mathrm{F} \\
\mathrm{Q}\end{array}$ & IC & FQ \\
\hline 1. & $\begin{array}{l}\text { Grinning face } \\
\text { with smiling eyes }\end{array}$ & (\#M2IAL1) & 1 & $\mathrm{NF}$ & & $\mathrm{NF}$ & & $\mathrm{NF}$ & & $\mathrm{NF}$ & & $\mathrm{NF}$ & \\
\hline 2. & OK Hand & $\mathrm{NF}$ & & (\#IALl) & 2 & $\mathrm{NF}$ & & $\mathrm{NF}$ & & $\mathrm{NF}$ & & $\mathrm{NF}$ & \\
\hline 3. & Beaming & $\mathrm{NF}$ & & (\#IAL1) & 1 & $\begin{array}{l}(\# \\
\text { M2 } \\
\text { IB } \\
\text { L1) }\end{array}$ & & $\mathrm{NF}$ & & $\mathrm{NF}$ & & $\mathrm{NF}$ & \\
\hline & TOTAL & & 1 & & 3 & & & & & & & & \\
\hline
\end{tabular}

Legend:

M2= Participant $2 \quad$ NF= Not Found

$\mathrm{FQ}=$ Frequency

IA= Iranian A

$\mathrm{IB}=$ Iranian B

$\mathrm{IC}=$ Iranian $\mathrm{C}$

Figure 2 Usage of Emoji in Opening Stage

In the first stage as shown in Figure 2, the Iranian business counterparts used more emoji than Malaysian participant (M2). Since this was the Opening Stage, they were greeted with an OK hand (once) and a beaming face (once). The data from the interaction between M2 and Iranian A (IA) revealed that M2 used emoji as non-verbal communication to give IA an indirect sign or hint about his feelings. M2 only used one emoji, which was grinning faces with smiling eyes. For example, M2 greeted IA using Salam which denotes an Islamic greeting along with the grinning face with smiling eyes emoji 3 . Meanwhile, IA used emoji for three times as a greeting in the Opening stage. For instance, he included two fingers' symbols $\int$ where they denote the OK Hand. This gesture, which showed the index finger and thumb touching to make an open circle, had the meaning of "I'm okay" or "yes, that's correct / good" (emojipedia.org, 2020). Meanwhile, there was no emoji used in the business interactions between M2 with Iranian B (IB) and Iranian C (IC). 


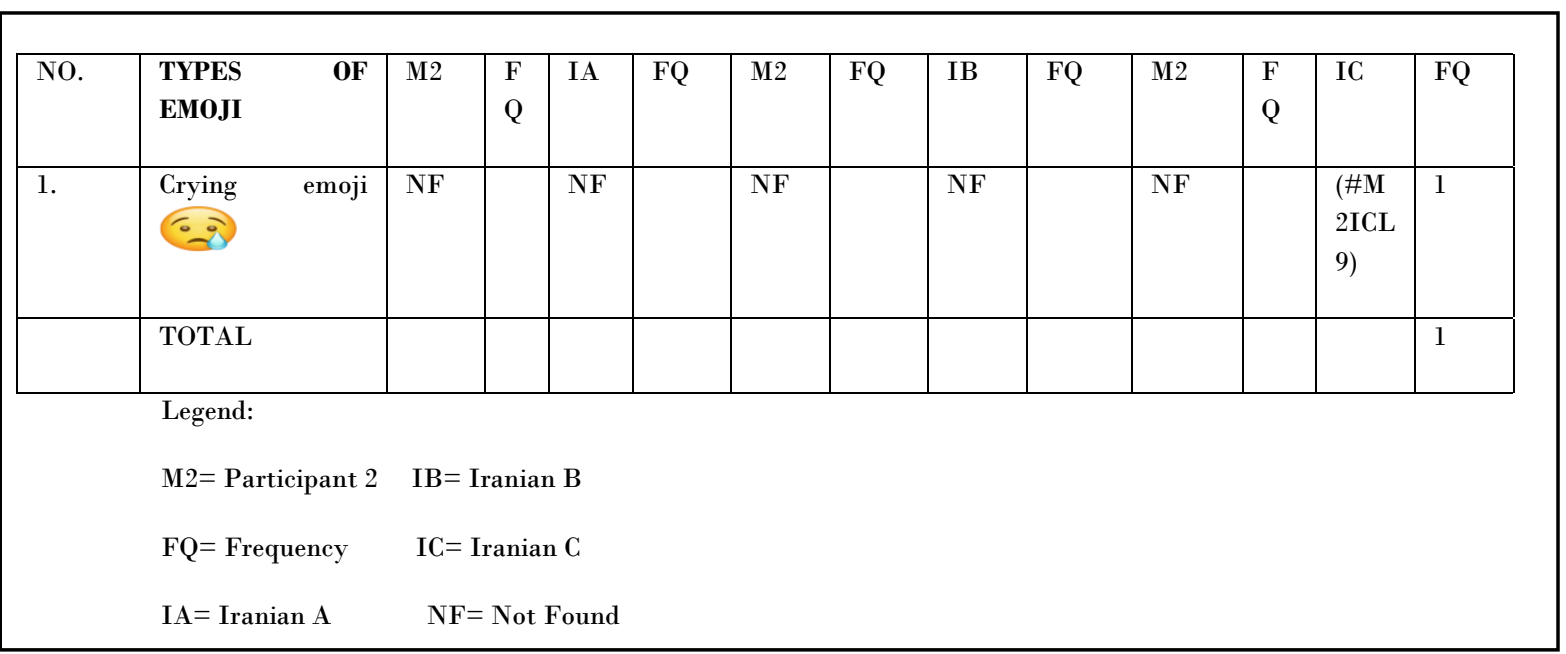

Figure 3 Usage of Emoji in Feedforward Stage

Figure 3 above describes the second stage, which was the Feedforward stage, where M2 only used one type of emoji to express his disappointment: the crying emoji (once). For instance, M2 was disappointed, and he emphasized this by saying, "Ohh really" followed by a crying emoji 0 . This WhatsApp symbol denotes a level of sadness or pain moderately (emojipedia.org, 2020). There was no emoji used in this stage between M2 with IA and IB.

The next stage was the Business Stage, which included a large number of interactions between the participants. M2 and IC used a lot of emoji during their business conversation. IC used emoji often, employing the red heart emoji fourteen times, the grinning face with sweat (once), the orange heart (once), see-no-evil (four times), 2-hearts (once), and the winking face (once) (twice). Meanwhile, M2 utilised a variety of emojis as shown such as thumbs up (four times), OK hand (twice) and one time of grimacing face emoji, folded hand, face screaming in fear, face with hand over mouth and smiling face. 


\begin{tabular}{|c|c|c|c|c|c|c|c|c|c|c|c|c|c|}
\hline \multicolumn{14}{|c|}{ Legend: } \\
\hline NO. & TYPES OF EMOJI & M2 & $F$ & $\begin{array}{l}\text { IA } \\
\end{array}$ & FQ & M2 & $\overline{F Q}$ & IB & FQ & M2 & FQ & IC & FQ \\
\hline 1. & thumbs-up $\frac{\beta}{8}$ & $\begin{array}{l}\text { (\#M2 } \\
\text { LIA } \\
\text { L28) }\end{array}$ & 1 & $\mathrm{NF}$ & & $\mathrm{NF}$ & & $\mathrm{NF}$ & & $\mathrm{NF}$ & & NF & \\
\hline 2. & folded hand & NF & & $\begin{array}{l}(\# \mathrm{I} \\
\mathrm{AL} \\
40)\end{array}$ & 1 & $\mathrm{NF}$ & & $\mathrm{NF}$ & & $\mathrm{NF}$ & & $\begin{array}{l}\text { (\#I } \\
\text { CL8 } \\
9)\end{array}$ & 1 \\
\hline 3. & Red heart & NF & & $\mathrm{NF}$ & & NF & & NF & & $\mathrm{NF}$ & & $\begin{array}{l}\text { (\#I } \\
\text { CL8 } \\
5\end{array}$ & 1 \\
\hline 4. & Orange heart & & & & & & & & & & & $\begin{array}{l}\text { (\#I } \\
\text { CL8 } \\
9)\end{array}$ & 1 \\
\hline & TOTAL & & 1 & 1 & & & & & & & & & 3 \\
\hline & $\begin{array}{l}\text { M2 }=\text { Participant } 2 \\
F Q=\text { Frequency } \\
\text { IA }=\text { Iranian A }\end{array}$ & \multicolumn{12}{|c|}{$\begin{array}{l}\mathrm{IC}=\text { Iranian } \mathrm{C} \\
\mathrm{NF}=\text { Not Found }\end{array}$} \\
\hline
\end{tabular}

Figure 4 Usage of Emoji in Feedback Stage

The following stage as shown in Figure 4 was Feedback Stage. The participants used four different forms of emoji, according to the figure. IC was the most regular user, using folded hand (once), red heart (once), and orange heart (once). M2 used a folded hand twice. Both M2 and IA used emoji once respectively where M2 asked again about the payment details by saying "(Forwarding message + please give me the information + folded hands emoji 2 . Meanwhile, IA also used the same emoji as M2 where he said "Thanks + folded hands emoji 20 " to show gratitude. Next, there was no emoji used in the Feedback stage between M2 with IB. In addition, there were 3 emoji used in this stage where IC had used most of the emoji. For example, IC apologised for the late reply by saying "Really sorry for being late I really apologize

The last stage was Closing Stage. Three types of emoji were used at this stage. There was a red heart, smiling face with hearts, and an emoji with a smiling face. IC used the red heart, while the other two were mentioned by M2. There were four emojis found in the business interaction between M2 and IC. For instance, to be polite, IC mentioned the gratitude words by saying "Hope you like them + red heart emoji " before closing their business interaction. 
The data from the interaction between the Malaysian participant and the IA revealed that M2 used more emoji than IA. When he used the crying emoji to express his disappointment, M2 used nonverbal communication to convey an indirect message or hint about his feelings to IA. Emoji expands its flexibility by providing a wide range of characters with emotional meanings, such as rage or fear that can be used in face-to-face interactions but are buried in text (Annamalai \& Abdul, 2017). Hence, they both used WhatsApp emoji to convey specific emotional meanings to the other person.

On the contrary, the findings from a business interaction between M2 and IB revealed that emoji was used less frequently in M2 and IB business communication. There was only one emoji discovered, which was used by M2. During the Opening stage, M2, for example, used a smiling face emoji to greet his clients with delight and as a conversation starter. Using emoji requires adding an appropriate tone to text messages or recommending changes to specific areas of the message's content (SwiftKey, 2015). To be more specific, this emoji is useful for starting conversations in business interactions.

Finally, throughout the business interaction between M2 and IC, a variety of emoji were used. When compared to other interactions, M2 and IC had the most usage of emoji. Despite the fact that both entrepreneurs used nearly the same number of emoji, IC used emoji significantly more frequently during the business interaction. IC, for instance, used a variety of emoji, including a red heart, an orange heart, a see-no-evil monkey face, and a sweating smiling face. This could be because IC is an expert in the use of technology in business interactions. The usage of emoji here is of variety where the emojis are used to express complex emotions (Hasan, 2018; Kelly \& Watts, 2015) and as contextualization signals (Al-Rashdi, 2015). They take place where words are difficult to be uttered in the WhatsApp conversations.

As a conclusion, this study has revealed several functions of social media in Business English among SME and business counterparts based on De Vito's Five-Stage Model of Conversation. It is in line with the study conducted by Kahar and Habil (2020) where the study focused on the emoji used in business between a Malaysian SME and his international business counterparts.

\subsection{CONCLUSION}

This paper investigates the use of emoji in business interactions. Based on the findings, this paper concludes that WhatsApp emoji serves a variety of functions in business interactions. It can have a positive, negative, or neutral connotation, indicating the emotions and approaches used in a conversation (Li \& Yang, 2018). WhatsApp has undoubtedly introduced some useful and valuable features for a variety of purposes, including business interactions. By making communication more efficient and convenient, WhatsApp can increase an individual's effectiveness. Hence, WhatsApp emoji offers a variety of benefits for users to understand each other's non-verbal communication better during business interactions.

Moreover, based on De Vito's Five-Stage Model of Conversation, the use of emoji in each stage served different purposes throughout the business dealings. Each emoji used in each stage emphasized the intention of the participants such as disappointment, happiness or apologetic. This is because how people use emoji at each stage will vary based on the communicators' personalities, the context in 
which the conversation takes place, the aim of the interaction, and a variety of other aspects discussed throughout this work (DeVito, 2011; Herwinda, 2012). Thus, by employing this conversation model, entrepreneurs can uncover a variety of uses for emoji in business communication.

\subsection{RECOMMENDATIONS}

In order to increase the usage of emoji in BELF, this study proposes several recommendations. To begin with, future research should include in-depth analyses of various instant messaging platforms such as Instagram, Telegram, and Twitter. Apart from WhatsApp, there are many other types of social media that have been used in online business interactions. For instance, future research can identify the functions of using selected emoji in Instagram when advertising the products on their "Instagram Feed". Furthermore, future studies could also compare the use of emoji in various social media platforms to determine which ones use emoji the most in relation to BELF. This could provide a diverse set of emoji used in business interactions across multiple platforms.

Next, future research should also seek to highlight the use of emoji in business interactions through the application of other theories such as Speech Act Theory and several others. Theories provide researchers with many "lenses" through which to see complex problems and social issues, allowing them to focus their attention on different parts of the data and offering a framework within which to conduct their analysis (Reeves, Albert, Kuper, \& Hodges, 2008; Cleland, 2017). Therefore, theories can provide researchers with a wide variety of possibilities and outcomes for using emoji in business interactions based on the BELF context.

\section{REFERENCES}

Adobe. 2019. Emoji Trend Report. SlideShare. Retrieved from https://www.slideshare.net/adobe/adobe-emoji-trend-report-2019.

Al Rashdi, F. 2015. Forms and Functions of Emojis in WhatsApp Interactions among Omanis. Unpublished Doctoral Dissertation, Georgetown University, Washington, USA.

Annamalai, S. \& Abdul S. S. 2017. Undergraduates' Interpretation on WhatsApp Smiley Emoji. Jurnal Komunikasi, Malaysian Journal of Communication. 33: 89-103. 10.17576/JKMJC-20173304-06.

Babai Shishavan, H. \& Sharifian, F. 2016. The Refusal Speech Act in a Cross-cultural Perspective: A Study of Iranian English-language Learners and Anglo-Australian Speakers. Language \& Communication. 47: 75-88. http://dx.doi.org/10.1016/j.langcom.2016.01.001.

Bengtsson, M. 2016. How to Plan and Perform a Qualitative Study Using Content Analysis. NursingPlus Open. 2: 8-14.

Business.com. 2020. Put a Smiley on It: Should You Use Emojis in Business Communication?

Retrieved from https:/www.business.com/articles/put-an-emoji-on-it-should-you-use-emojis-inbusiness-communication/.

Casado-Molina, A.N., Garcia, M.M. R., \& Romero-Charneco, Alarcon-Urbistondo, \& P., Romero- 
Charneco, M. 2019. Exploring the Opportunities of the Emojis in Brand Communication: The Case of Beer Industry. International Journal of Business Communication. March. 232948841983296. https//: doi:10.1177/2329488419832964.

Cleland J. A. 2017. The Qualitative Orientation in Medical Education Research. Korean Journal of Medical Education. 29(2): 61-71. https://doi.org/10.3946/kjme.2017.53.

Creswell, J. W. 1998. Qualitative Inquiry and Research Design. Choosing Among Five Traditions. Thousand Oaks: Sage.

Creswell, J. W. 2003. Research Design. Qualitative, Quantitative, and Mixed Method Approaches. $2^{\text {nd }}$. ed. Thousand Oaks: Sage.

Cresswell, J. W. 2009. Research Design. Qualitative, Quantitative and Mixed Methods Approaches. USA: Sage.

DeVito, J. A. 2013. Interpersonal Communication. United States: Pearson.

Devito, J. A. 2011 . Interpersonal Messages: Communication and Relationship Skills. Second Edition. United States: Pearson Education, Inc.

Erlingsson, C. \& Brysiewicz, P. 2017. A Hands-on Guide to Doing Content Analysis. African Journal of Emergency Medicine. 7: 93-99.

Hasan, A. F. 2018. The Role of Emojis and Emoticons in Enhancing Interpersonal Communication through Messenger and WhatsApp Applications. Journal of Adab Al-Kufa. 2(37): 115-130.

Hendrith, M. 2018. The Effects Culture and Communication Have on Businesses. Integrated Studies. 120.

Herwinda, H. 2012. Analysis of Expressions Used by An Insurance Agent in Prospecting A Client: A Discourse Analysis. Doctoral Dissertation, President University.

Huang, G.H., Chang, C. T., Bilgihan, A., \& Okhomus, F. 2020. Helpful or Harmful? A Double-edged Sword Emoticons in Online Review Helpfulness. Tourism Management. 81: 104135.

Huotari, L., Ulkuniemi, P., Saraniemi, S., \& Tormala, M. 2015. Analysis of Content Creation in Social Media by B2B Companies. Journal of Business \& Industrial Marketing. 30: 761-770. https://doi: 10.1108/JBIM-05-2013-0118.

Intan, N. A., \& Yasir, A. 2020. Cultural Interpretation of Emoji in Malaysian Context. European $\begin{array}{lllll}\text { Proceedings of Social and Behavioural Sciences. } & \text { 2357-1330. }\end{array}$ https://doi:10.15405/epsbs.2020.10.02.70.

Jakic, A., Wagner, M., \& Meyer, A. 2017. The Impact of Language Style Accommodation during Social Media Interactions on Brand Trust. Journal of Service Management. 28: 00-00. https//: doi:10.1108/JOSM-12-2016-0325.

Kahar, R. \& Habil, H. (2020). An Analysis of WhatsApp Emoji in Business Interactions between a Malaysian SME and the Turkish Counterparts. LSP International Journal. 7(1): 27-37.

Kelly, R., \& Watts, L. 2015. Characterising the Inventive Appropriation of Emoji as Relationally Meaningful in Mediated Close Personal Relationship. Paper presented at European Conference on Computer Supported Cooperative Work (ECSCW), Oslo, Norway.

Li, L., \& Yang, Y. 2018. Pragmatic Functions of Emoji in Internet-based Communication-A Corpusbased Study. Asian-Pacific Journal of Second and Foreign Language Education. 16(3). https://doi.org/10.1186/s40862-018-0057-z.

Mayring, P. 2014. Qualitative Content Analysis: Theoretical Foundation. Basic Procedures and Software Solution. Klagenfurt. Retrieved from https://nbn-resolving.org/urn:nbn:de:0168-ssoar-395173.

McShane, L., Pancer, E., Poole, M., \& Deng, Q. 2020. Emoji, Playfulness, and Brand Engagement on Twitter. Journal of Interactive Marketing. 53: 96-100.

Mert, G. 2020. The Role of Use of Emoji in Business on Communication and Employment Motivation. International Journal of Disciplines Economics \& Administrative Scienves Studies. 6(18): 397-406. 
Parganas, P., Anagnostopoulos, C., Chadwick, S. 2017. Effects of Social Media Interactions on Brand Associations: A Comparative Study of Soccer Fan Clubs. International Journal of Sport Management and Sponsorship. 18: 149-165. https://doi: 10.1108/IJSMS-05-2017-087.

Reeves, S., Albert, M., Kuper, A., \& Hodges, B. D. 2008. Why Use Theories in Qualitative Research? Bmj. 337.

Robinson, B. September 7, 2019. Emojis: An Essential Tool for Innovative Business Communication? Forbes.

Retrieved from https://www.forbes.com/sites/bryanrobinson/2019/09/07/emojis-an-essential-toolfor-innovative-business-communication-really/? $\mathrm{sh}=\mathrm{ffcb} 7 \mathrm{~d} 2 \mathrm{c} 9 \mathrm{e} 65$.

Sharifian, F. 2014. Cultural Schemas as Common Ground. In Wrestling with Words and Meanings: Essays in Honour of Keith Allan (pp. 219-235). Monash University Publishing.

Sharma, A., Sharma, S., \& Chaudhary, M. 2020. Are Small Travel Agencies Ready for Digital Marketing? Views of Travel Agency Managers. Tourism Management. 79: 104078.

Skiba, D. J. 2016. Face with Tears of Joy is Word of the Year: Are Emoji a Sign of Things to Come in Health Care? Nursing Education Perspectives. 37(1): 56-57.

SwiftKey. 2015. SwiftKey Emoji Report. April 2015. United State: TouchType Limited.

Yus, F. 2014. Not All Emoticons are Created Equal. Linguagem em (Dis)curso. 14(3): 511-529. https://doi.org/10.1590/1982-4017-140304-0414.

Zeybek, I. 2017. Dijitalde Duygu Dili: Emojilerin Sihirli Dünyası. Uluslararası Kıbrıs Üniversitesi, “Dönüşen Dünyada İletişimin Rolü” Uluslararası Sempozyum Kitabı içinde. 398- 416.

Zhang, Y. \& Wildemuth, B. M. 2005. Human Brain Mapping. 30(7): 2197-2206. 